\title{
PEComa hepático: un tumor inusual en una localización infrecuente
}

\section{Hepatic PEcoma: an unusual tumor in an infrequent location}

\author{
$M^{a}$ Ángeles Sánchez-Gálvez ${ }^{*}$, Pablo Parra-Membrives ${ }^{1}, M^{a}$ Luisa Sánchez-Bernal ${ }^{2}$ \\ Darío Martínez-Baena ${ }^{1}$, José M. Lorente-Herce ${ }^{1}$ y Granada Jiménez-Riera ${ }^{1}$ \\ ${ }^{1}$ Unidad de Cirugía Hepatobiliopancreática, Hospital Virgen de Valme; ${ }^{2}$ Servicio de Anatomía Patológica, Hospital Virgen de Valme, Sevilla, España
}

\section{Resumen}

Los tumores de células neoplásicas perivasculares epitelioides (PEComas) son una familia de tumoraciones caracterizada apenas un par de décadas antes. Componen un grupo inusual de neoplasias, que puede aparecer en distintas localizaciones del organismo. Por lo general, los PEComas se consideran tumores benignos, pero hay ciertas características histológicas que hacen de algunos subgrupos lesiones sospechosas de una malformación maligna. El tratamiento de estos tumores consiste en la resección quirúrgica, pero no existe tratamiento oncológico por completo eficaz. Se presenta el caso clínico de una mujer sometida a la resección de una lesión hepática con diagnóstico posterior de PEComa con rasgos de proceso maligno.

Palabras Clave: PEComa. PEComa hepático. Tumores mesenquimales. Neoplasia de células epitelioides perivasculares.

\begin{abstract}
Perivascular epithelioid cell neoplasms (PEComas) are a tumor family defined as such just a couple of decades ago. They make an unusual group of neoplasms, which can appear in different locations of the organism. PEComas are usually considered to be benign tumors, but there are some histological features that make some subgroups suspicious of malignancy. The treatment of these tumors consist in their surgical resection, with no current effective complementary oncological treatment known. We present the clinical case of a woman that underwent surgery for a resection of a hepatic lesion labeled afterwards as a PEComa with malignant features.
\end{abstract}

Key Words: PEComa. Hepatic PEComa. Mesenchymal tumors. Perivascular epithelioid cell neoplasm.

\section{Introducción}

Los PEComas (o tumores de células neoplásicas perivasculares epitelioides) constituyen una familia de tumores de reciente clasificación. La OMS los considera tumores mesenquimales de células epitelioides perivasculares con una histología e inmunohistoquímica distintivas. En la década de 1990 se agruparon por primera vez como entidad diferenciada y se observaron en un principio en los tumores de células claras del pulmón y los angiomiolipomas. Con posterioridad se han relacionado también con la linfagiomiomatosis y un amplio y diverso número de

\footnotetext{
Correspondencia:

*Ma Ángeles Sánchez-Gálvez

Ctra. de Cádiz, Km. 548,9

C.P. 41014, Sevilla, España

Fecha de recepción: 05-02-2019

Cir Cir. 2020;88(2):215-218

E-mail: msgalvez91@gmail.com

Fecha de aceptación: 17-05-2019

DOI: $10.24875 / C I R U .19001093$

Contents available at PubMed

www.cirugiaycirujanos.com

0009-7411/@ 2019 Academia Mexicana de Cirugía. Publicado por Permanyer. Este es un artículo open access bajo la licencia CC BY-NC-ND (http://creativecommons.org/licenses/by-nc-nd/4.0/).
} 
tumores viscerales, de tejidos blandos y óseos. También se ha observado una conexión entre esta familia de tumores y la esclerosis tuberosa.

En el plano macroscópico, los PEComas evolucionan habitualmente como masas en crecimiento, no infiltrativas y a menudo con focos hemorrágicos en su interior. Presentan vasos de gran calibre y tortuosos en el espesor de la neoplasia.

En términos microscópicos, la presencia de células epitelioides es típica y se disponen siempre en la muscular del vaso, comprometen su luz y reemplazan al tejido muscular liso normal y al colágeno. Asimismo, se pueden observar células fusiformes o células con acúmulos de lípidos, lo que hace algunas veces difícil el diagnóstico diferencial con otros tumores, por ejemplo los tumores del músculo liso, los carcinomas y los tumores adipocíticos ${ }^{1}$.

En fecha reciente se ha observado una tendencia de ciertos PEComas a convertirse en malformaciones malignas dado que poseen la capacidad de infiltrar y metastatizar. Se ha establecido una serie de criterios para sospechar una naturaleza maligna, incluidos el tamaño del tumor $>5 \mathrm{~cm}$, el patrón infiltrativo de crecimiento, la presencia de núcleo grande e hipercrómico, la necrosis tumoral y la actividad mitótica $>1 / 50$ replicaciones por campo. Se considerarían malignos los PEComas que tuvieran dos o más de estas características².

El tratamiento óptimo de este tipo de tumores, dada su baja incidencia, es todavía una incógnita.

\section{Caso clínico}

Se presenta el caso de una mujer de 50 años, diabética, con mal control de la glucemia y dislipémica, que ingresó en el servicio de medicina interna por fiebre alta de 10 días de evolución, con repercusión del estado general (bacteriemia), dolor en fosa renal derecha y clínica miccional. En este contexto, al sospechar una pielonefritis aguda de causa obstructiva, se solicitó una ecografía abdominal que identificó una lesión ocupante de espacio (LOE) hepática de $8.9 \times$ $9.4 \mathrm{~cm}$ en el segmento VI. Dicha LOE se describió como isoecogénica, redondeada y bien definida con una cápsula fina hiperecogénica, con imágenes puntiformes hipodensas en su espesor y con clara vascularización intralesional.

Durante el ingreso se realizó un estudio completo de la lesión mediante resonancia magnética (RM) hepática dinámica (Fig. 1), que delineó la lesión y se determinó que presentaba características consistentes

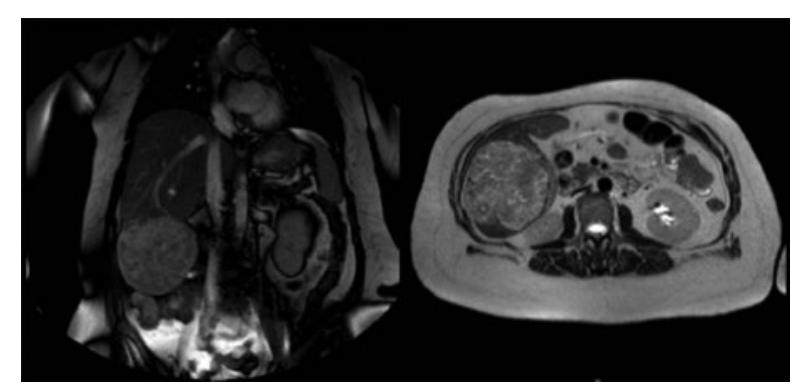

Figura 1. Lesión en la resonancia magnética.

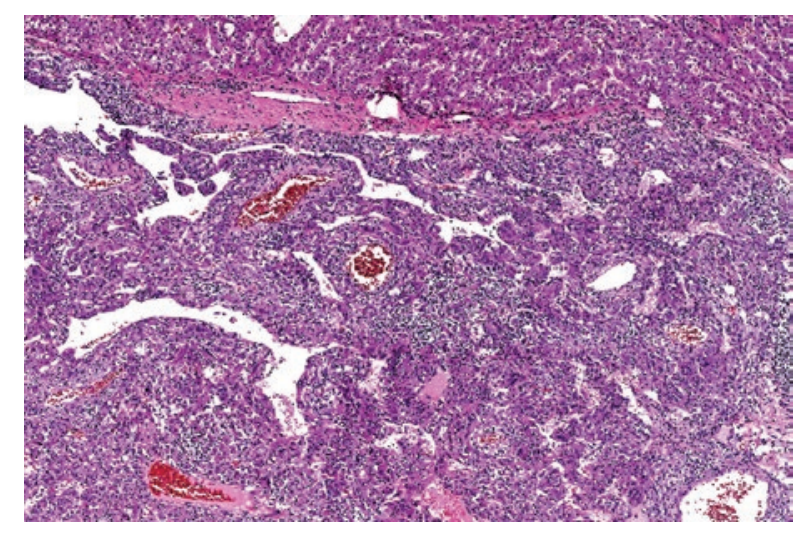

Figura 2. Imagen al microscopio $(4 x)$ de PEComa teñido con hematoxilina-eosina.

con adenoma hepático de $9.6 \times 9.6 \times 9.3 \mathrm{~cm}$ de tamaño. La realización de una colonoscopia, una gastroscopia y una tomografía computarizada (TC) de extensión no detectó otras alteraciones adicionales. La unidad de los autores valoró a la paciente y la programó para una hepatectomía laparoscópica del segmento $\mathrm{VI}$, dados el tamaño de la lesión, el riesgo de sangrado y la malignización, que se practicó sin incidencias.

La enferma recibió el alta al quinto día postoperatorio sin ninguna complicación. El resultado de la anatomía patológica mostró la existencia de un PEComa (angiomiolipoma epitelioide monotípico) mayor de $10 \mathrm{~cm}$, con presencia de extensas áreas de necrosis en su interior y ausencia de permeación vascular. En el plano microscópico, la neoplasia se encontraba separada del hígado por una seudocápsula fibrosa, y estaba constituida por células epitelioides, poligonales, algunas veces fusiformes, y dispuestas de forma perivascular. Dichas células presentaban abundante citoplasma eosinófilo, claro de modo ocasional, con núcleos vesiculares grandes y atípicos, y nucléolo predominante (Figs. 2 y 3), signos típicos de este tipo de tumores. Se realizó inmunohistoquímica, también consistente con PEComa: positivo para vimentina, AML, HMB45 (Fig. 4) y Melan-A (Fig. 5), y negativo para proteína $\mathrm{S} 100$ y desmina. Se determinó 


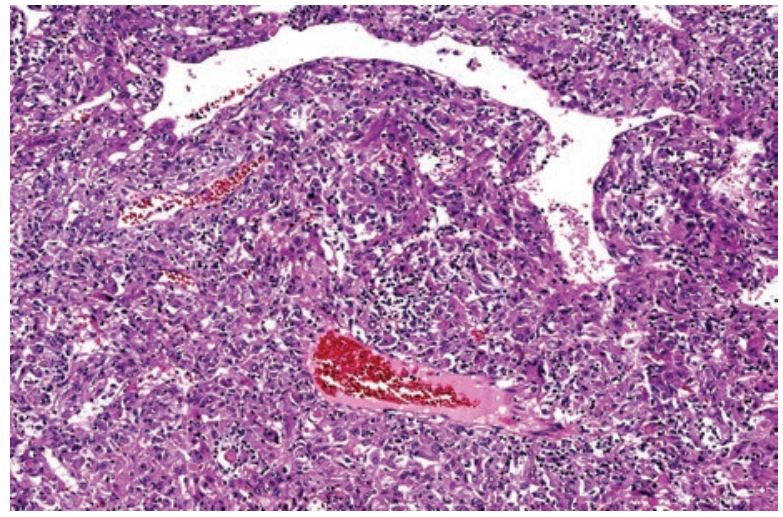

Figura 3. Imagen al microscopio (10x) de PEComa teñido con hematoxilina-eosina.

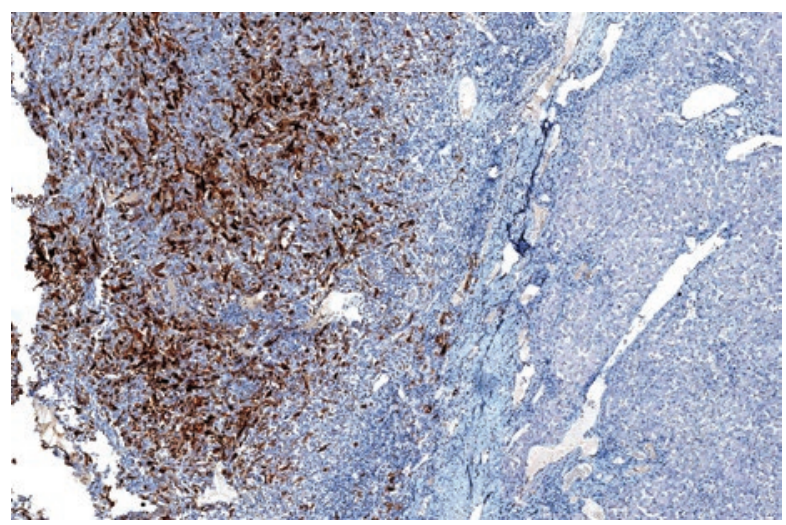

Figura 4. Estudio inmunohistoquímico (4x) positivo para marcadores de músculo liso (HMB45).

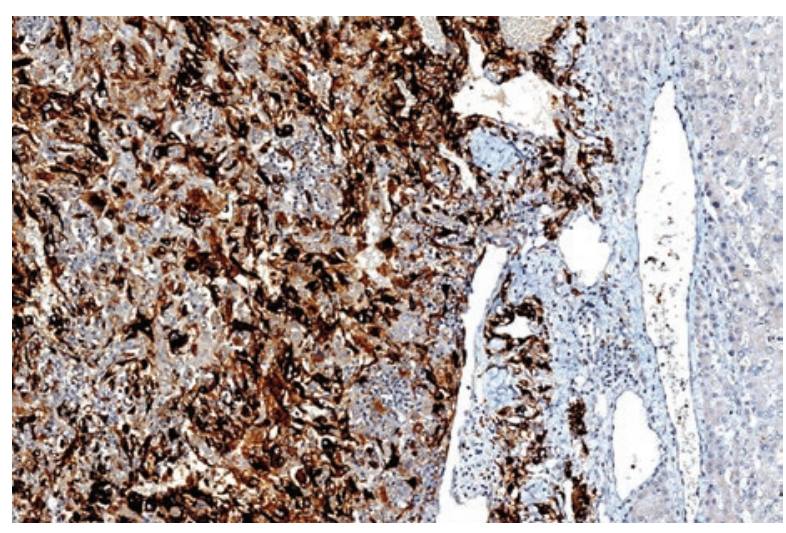

Figura 5. Estudio inmunohistoquímico (10x) positivo para marcadores melanocíticos (MELAN-A).

a su vez el índice proliferativo mediante Ki67, que fue del $10 \%$.

Dadas las características que presentaba el tumor (tamaño tumoral $>10 \mathrm{~cm}$, extensas áreas de necrosis y bordes expansivos), contaba con factores de mal pronóstico. Se planificó un seguimiento estrecho en consultas externas de esta paciente mediante pruebas de imagen cada seis meses durante los primeros dos años y de forma anual después.

\section{Discusión}

Los PEComas hepáticos son una entidad rara. En la actualidad sólo hay 24 referencias de este tumor en las publicaciones médicas, y alrededor de 33 casos notificados, de los cuales sólo cuatro presentaron características de malignidad e incluso metástasis a distancia. Estos tumores, aunque pueden aparecer en cualquier localización anatómica, suelen hallarse en los riñones o el útero. Parecen predominar en pacientes mujeres de 30 a 50 años, si bien pueden diagnosticarse a cualquier edad.

El diagnóstico del PEComa antes de la operación es muy difícil debido a la similitud de su apariencia en pruebas de imagen respecto de otras lesiones hepáticas, en particular el adenoma. Su diagnóstico es casi siempre incidental en la pieza quirúrgica, ya que no causan síntomas. Si existe una sospecha preoperatoria es aconsejable la realización de una biopsia de la lesión hepática ${ }^{3,4}$.

Hoy en día se sabe poco del tratamiento de este tipo de tumores, en virtud de su rareza. La mayoría de PEComas se considera benigna. Sin embargo, hay ciertas características histológicas que llevan a sospechar una naturaleza maligna ante una neoplasia de esta familia de tumores. En este subgrupo de riesgo está indicada la resección quirúrgica de la lesión con márgenes libres de enfermedad y el seguimiento estrecho para documentar posibles recidivas locales e incluso lesiones metastásicas.

En el caso de establecer un diagnóstico preoperatorio e identificar un tumor grande (irresecable de modo inicial), se consideran en la actualidad nuevos tratamientos neoadyuvantes para favorecer la posibilidad de resección. La administración de un inhibidor de la mTOR como sirolimus ha demostrado ser efectiva en angiomiolipomas y hasta el momento se ha usado en un caso de PEComa hepático para conseguir una resección R0, con buenos resultados ${ }^{5-7}$. Otra opción en vías de investigación es la radioterapia neoadyuvante. En el trabajo de Kirste, et al., fue posible la reducción del tamaño tumoral de un PEComa hepático mediante la administración de ocho sesiones de radioterapia estereotáctica con $7.5 \mathrm{~Gy}$, sin complicaciones ${ }^{8}$.

\section{Financiamiento}

No se recibió ningún financiamiento para la elaboración de esta revisión. 


\section{Conflicto de intereses}

Los autores declaran no tener conflicto de interés alguno.

\section{Agradecimientos}

Los autores agradecen a la doctora María Luisa Sánchez-Bernal por la cesión de las imágenes de anatomía patológica de la pieza quirúrgica.

\section{Responsabilidades éticas}

Protección de personas y animales. Los autores declaran que para esta investigación no se han realizado experimentos en seres humanos ni en animales.

Confidencialidad de los datos. Los autores declaran que han seguido los protocolos de su centro de trabajo sobre la publicación de datos de pacientes.
Derecho a la privacidad y consentimiento informado. Los autores han obtenido el consentimiento informado de los pacientes y/o sujetos referidos en el artículo. Este documento obra en poder del autor de correspondencia.

\section{Bibliografía}

1. Folpe AL, Kwiatkowski DJ. Perivascular epithelioid cell neoplasms: pathology and pathogenesis. Human Pathology. 2010; 41: 1-15

2. Haiges D, Kurz P, Laaff H, Meiss F, Kutzner H, Technau-Hafsi K. Malignant PEComa. J Cutan Pathol. 2018; 45 (1): 84-89.

3. Bergamo F, Maruzzo M, Basso U, Montesco MC, Zagonel V, Gringeri E, et al. Neoadjuvant sirolimus for a large hepatic perivascular ephitelioid cell tumor (PEComa). World J Sure Oncol. 2014; 12 : 46.

4. Kirnap M, Ozgun G, Moray G, Haberal M. Perivascular epithelioid cell tumor outgrowth from the liver. Int J Surg Case Rep. 2018; 53:295-298.

5. Dezman R, Masulovic D, Popovic P. Hepatic perivascular epithelioid cell tumor: a case report. Our J Radiol Open. 2018; 21(5): 121-125.

6. Cardoso H, Silva M, Vilas-Boas F, Cunha R, Lopes J, Costa Maia J, et al. Hepatic perivascular epithelioid tumor (PEComa). A case report. Clin Res Hepatol Gastroenterol. 2017; 41: 43-46.

7. Kenerson H, Folpe AL, Takayama TK, Yeung RS. Activation of the mTOR pathway in sporadic angiomyolipomas and other perivascular epithelioid cell neoplasms. Hum Pathol. 2007; 38(9): 1361-1371.

8. Kirste S, Kayser G, Zipfel A, Grosu AL, Brunner T. Unresectable hepatic PEComa: a rare malignancy treated with stereotactic body radiation therapy (SBRT) followed by complete resection. Radiat Oncol. 2018;13(1): 28. 